\title{
The kinetic energies of left ventricular 4D flow components correlate with established markers of prognosis and represent novel imaging biomarkers in both ischaemic and dilated cardiomyopathy
}

\author{
Victoria Stoll ${ }^{1 *}$, Aaron T Hess ${ }^{1}$, Jonatan Eriksson², Petter Dyverfeldt ${ }^{2}$, Tino Ebbers², Saul G Myerson ${ }^{1}$, \\ Carl Johan Carlhall ${ }^{2}$, Stefan Neubauer ${ }^{1}$
}

From 19th Annual SCMR Scientific Sessions

Los Angeles, CA, USA. 27-30 January 2016

\section{Background}

Despite different aetiology of myocardial damage in dilated cardiomyopathy (DCM) and ischaemic cardiomyopathy (IHD), cardiac remodelling occurs in both, culminating in the end result of a dilated left ventricle with impaired function. Cardiac remodelling is a complex process in which numerous cellular, mechanical and flow processes become deranged. Insights into changes of multidimensional flow patterns and kinetic energy (KE) within the left ventricle are now afforded by the use of $4 \mathrm{D}$ flow CMR.

We hypothesised that greater derangements in $4 \mathrm{D}$ flow measures would relate to: 1 ) decreased mechanical cardiac function and dilatation, as assessed by LV ejection fraction (LVEF), LV myocardial strain and LV volumes, 2) increased levels of biochemical remodelling markers and 3) worsening patient symptoms and functional capacity. We hypothesised these changes to be independent of the initial aetiology of the myocardial damage, instead reflecting the self-propagating nature of cardiac remodelling.

\section{Methods}

98 subjects (34 DCM patients, 30 IHD patients and 34 healthy controls) underwent CMR imaging for anatomy, tagging and 4D flow. The LV volume was analysed in 4 functional flow components; direct flow, delayed ejection flow, retained inflow and residual volume. The kinetic

OCMR, University of Oxford, Oxford, UK

Full list of author information is available at the end of the article energy (KE) for these components was measured at end diastole.

\section{Results}

Both patient groups had significantly decreased direct flow compared to controls (DCM $11 \pm 6 \%$, IHD $14 \pm 9 \%$ vs $38 \pm 4 \% \mathrm{P}<0.0001)$ and increased residual volume (DCM $51 \pm 11 \%$, IHD $49 \pm 10 \%$ vs $30 \pm 4 \% \mathrm{P}<0.0001$ ) (fig $1 \mathrm{~A}$ ). The kinetic energy profile was significantly different for the direct flow (DCM $0.19 \pm 0.17 \mathrm{~mJ}$, IHD $0.25 \pm 0.22 \mathrm{~mJ}$ vs $0.46 \pm 0.19 \mathrm{~mJ}, \mathrm{P}<0.0001)$ and the residual volume (DCM $0.47 \pm 0.43 \mathrm{~mJ}$, IHD $0.32 \pm 0.30 \mathrm{~mJ}$ vs $0.05 \pm$ $0.03 \mathrm{~mJ}, \mathrm{P}<0.0001)$ between the patient groups compared to controls (fig 1B).

LVEF and strain were significantly impaired in patients vs controls (Figure 2). Direct flow KE correlated positively to the $\operatorname{LVEF}(\mathrm{r}=0.65), 6$ minute walk test $(6 \mathrm{MWT})(\mathrm{r}=0.46)$ and negatively to the LVEDV $(\mathrm{r}=-0.35), \operatorname{LVESV}(\mathrm{r}=-0.54), \mathrm{BNP}(\mathrm{r}=-0.45), \mathrm{LV}$ strain $(r=-0.56)$ and Minnesota HF questionnaire (MHFQ) ( $\mathrm{r}=-0.55)$ (fig 1C). Residual volume KE correlated negatively to the LVEF $(\mathrm{r}=-0.87), 6 \mathrm{MWT}$ $(\mathrm{r}=-0.49)$, and positively to the LVEDV $(\mathrm{r}=0.79)$, $\operatorname{LVESV}(r=0.89)$, BNP $(r=0.53)$,LV strain $(r=0.79)$ and MHFQ $(r=0.58)$. All $\mathrm{P}$ values for correlations $\mathrm{P}<0.0001$.

\section{Conclusions}

Both DCM and IHD patients demonstrated less efficient blood flow patterns with deranged kinetic energy profiles compared to controls. The greater the derangement of flow parameters from normal, the worse the myocardial 


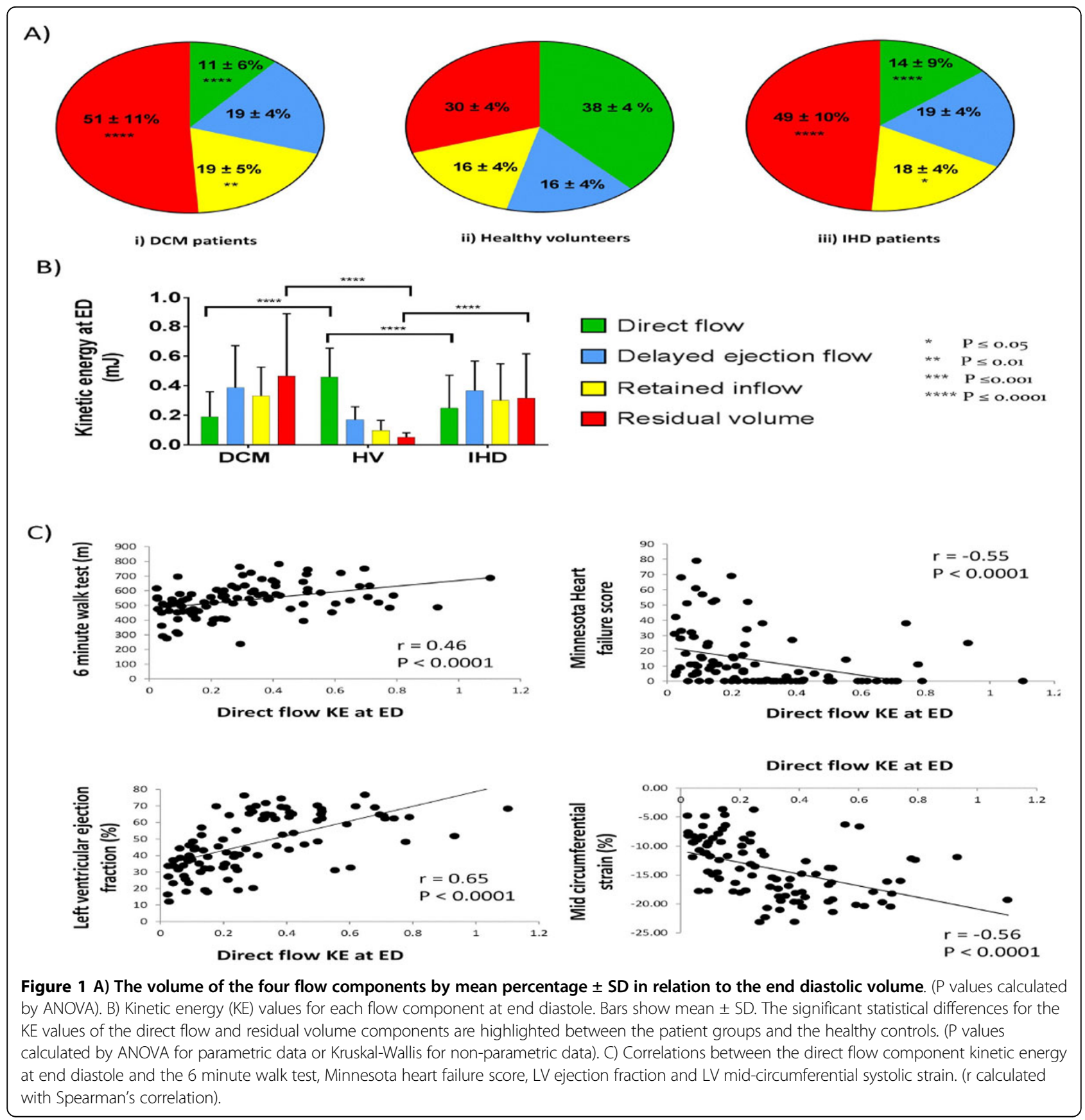

function, dilatation, BNP, 6 MWT and patient symptoms, irrespective of the initial pathology. This is the first study to suggest that derangements in $4 \mathrm{D}$ flow parameters are novel biomarkers of disease severity in cardiomyopathy patients and correlate with established markers of cardiac remodelling and prognosis, which may provide additive value in monitoring novel heart failure therapies and predicting prognosis.
Authors' details

'OCMR, University of Oxford, Oxford, UK. ${ }^{2}$ Division of Cardiovascular Medicine, Linköping University, Linköping, Sweden.

Published: 27 January 2016

\section{doi:10.1186/1532-429X-18-S1-068}

Cite this article as: Stoll et al:: The kinetic energies of left ventricular 4D

flow components correlate with established markers of prognosis and represent novel imaging biomarkers in both ischaemic and dilated cardiomyopathy. Journal of Cardiovascular Magnetic Resonance 201618 (Suppl 1):068. 


\begin{tabular}{|c|c|c|c|c|}
\hline & $\begin{array}{l}\text { Healthy } \\
\text { volunteers } \\
(n=34)\end{array}$ & $\begin{array}{l}\text { DCM patients } \\
\qquad(n=34)\end{array}$ & $\begin{array}{l}\text { IHD patients } \\
\qquad(n=30)\end{array}$ & $P$ value \\
\hline \multicolumn{5}{|c|}{ Demographics } \\
\hline $\begin{array}{l}\text { Age } \\
\text { (yrs) }\end{array}$ & $58 \pm 11$ & $57 \pm 14$ & $63 \pm 12$ & 0.11 \\
\hline $\begin{array}{c}\text { Male } \\
\mathrm{n}(\%) \\
\end{array}$ & $24(71)$ & $22(65)$ & $28(93)$ & 0.02 \\
\hline $\begin{array}{c}\text { Body mass index } \\
\left(\mathrm{kg} / \mathrm{m}^{2}\right) \\
\end{array}$ & $26 \pm 4$ & $27 \pm 6$ & $28 \pm 4$ & 0.009 \\
\hline $\begin{array}{c}\text { Systolic BP } \\
(\mathrm{mmHg})\end{array}$ & $135 \pm 21$ & $128 \pm 18$ & $120 \pm 15$ & 0.01 \\
\hline $\begin{array}{c}\text { Diastolic BP } \\
(\mathrm{mmHg}) \\
\end{array}$ & $79 \pm 10$ & $72 \pm 12$ & $69 \pm 9$ & 0.001 \\
\hline $\begin{array}{c}\text { Heart rate } \\
\text { (bpm) }\end{array}$ & $65 \pm 13$ & $65 \pm 14$ & $65 \pm 14$ & 0.88 \\
\hline \multicolumn{5}{|c|}{ Prognostic markers } \\
\hline $\begin{array}{c}\text { BNP } \\
(\mathrm{pmol} / \mathrm{L}) \\
\end{array}$ & $7 \pm 5$ & $50 \pm 104$ & $77 \pm 108$ & $<0.0001$ \\
\hline $\begin{array}{c}6 \text { minute walk test } \\
(\mathrm{m}) \\
\end{array}$ & $625 \pm 78$ & $500 \pm 84$ & $470 \pm 101$ & $<0.0001$ \\
\hline $\begin{array}{l}\text { Minnesota Heart Failure } \\
\text { Questionnaire }\end{array}$ & $0 \pm 0$ & $18 \pm 19$ & $22 \pm 22$ & $<0.0001$ \\
\hline \multicolumn{5}{|c|}{ CMR results } \\
\hline $\begin{array}{c}\text { LV EF } \\
(\%) \\
\end{array}$ & $67 \pm 4$ & $36 \pm 11$ & $39 \pm 12$ & $<0.0001$ \\
\hline $\begin{array}{c}\text { LV EDV } \\
(\mathrm{ml}) \\
\end{array}$ & $158 \pm 30$ & $273 \pm 118$ & $231 \pm 68$ & $<0.0001$ \\
\hline $\begin{array}{c}\text { Left atrial EF } \\
(\%) \\
\end{array}$ & $56 \pm 6$ & $39 \pm 12$ & $38 \pm 14$ & $<0.0001$ \\
\hline LV sphericity index & $1.7 \pm 0.2$ & $1.4 \pm 0.2$ & $1.4 \pm 0.2$ & $<0.0001$ \\
\hline $\begin{array}{c}\text { Peak systolic circumferential } \\
\text { strain (\%) } \\
\end{array}$ & $-19 \pm 3$ & $-10 \pm 4$ & $-12 \pm 4$ & $<0.0001$ \\
\hline $\begin{array}{c}\text { Peak diastolic circumferential } \\
\text { strain rate }\left(\mathrm{s}^{-1}\right)\end{array}$ & $83 \pm 19$ & $48 \pm 21$ & $51 \pm 20$ & $<0.0001$ \\
\hline
\end{tabular}

Figure 2 Values are mean \pm SD. P values calculated by ANOVA for parametric data or Kruskal-Wallis for non-parametric data. 